\title{
ASPECTS REGARDING A NEW METHODOLOGY FOR ACTIVE PORTFOLIO MANAGEMENT OF HEDGE FUNDS ALTERNATIVE IN EMERGING MARKETS- THE CASE OF ROMANIAN CAPITAL MARKET IN THE ACTUAL CONTEXT OF POST-CRISIS RECOVERY
}

\author{
Eugen-Silviu VRĂJITORU*, Mircea BOSCOIANU*, Elena-Corina BOSCOIANU** \\ *"Transilvania" University of Brașov, Romania \\ **INCAS Bucharest, Romania \\ eugen.vrajitoru@unitbv.ro; boscoianu.mircea@yahoo.com; \\ boscoianu.corina@incas.ro
}

\begin{abstract}
In emerging markets, the processes in portfolio management should be adapted according to the typical constraints (market liquidity aspect and other market imperfections)that limits the use of alternative instruments / strategies and diversification capabilities. The aim is to develop a new way to understand and implement innovative solutions in real portfolio management in the case of Romanian capital market. The innovation is based on a scalable hedge-fund (HF) structure that capture different alternative instruments. This HF architecture represents a versatile dynamic AIF, equipped with capabilities to integrate the synergies between diversification based on alternative instruments but also the diversification based on alternative strategies and it integrates a core thematic sub-portfolio and 2-4 satellite rotating sub-portfolios capable to compensate the impossibility to use short sales and leverage strategies.
\end{abstract}

Keywords: active portfolio management, alternative investment funds (AIFs), hedge fund (HF) architecture; sub-portfolio selection, post-crisis recovery

\section{Introduction}

The portfolio management of alternative investment funds in emerging markets is different from the developed markets (because of the typical constraints on the real diversification possibilities, problems with liquidity, robustness and market resilience). The processes in portfolio management should be adapted according to all these constraints [1], [2], [3]. Although the fact that emerging markets represents only a very small segment for global investors for reasons of diversification there is a growing interest in these types of markets and there is even a competition at the level of portfolio managers. In the case of Romanian capital market there are two major events that will change the paradigm: there is a new status of the Romanian capital market (just upgraded in 2021 to the emerging market status) and the recent Alternative Investment Fund AIF Law 2020 (with potential significant impact in the dynamics of all types of mutual and investment funds but also, more important, on the culture of investments and the process of formation of a critical mass of investors (retail and institutional) in Romanian emerging capital market). The main objective is to develop a new scalable and modular framework for understanding the typical strategies (or mix of strategies) for an active portfolio management in the case of Romanian 
capital market. Even after the change of the status of the emerging market, the problems in the Romanian capital market remain persistent and still refer to a low liquidity and a low interest of investors, but the good news related to the multiples of prices and also good dividends represents very attractive arguments for long-term global investors [4]. The application is related to the case of a possible development of an alternative investment fund (AIF) structure or architecture represented by a hedge-fund (HF). This HF architecture dedicated for emerging markets applications represents a versatile AIF, equipped with capabilities to integrate both alternative instruments but also alternative strategies) should respond to the typical constraints in emerging markets that reduce the maneuvering possibilities. This HF architecture is also an innovative one because we consider a core (thematic or basic) sub-portfolio and 2-4 satellite rotating sub-portfolios. The interest is to compensate the limits of an emerging market (beside the actual impossibility to engage derivatives the Romanian BSE is also characterized by poor liquidity; poor diversification capabilities and a poor market deepens). In the actual context of Romanian capital market (there are constraints for short-sales and leverage operations until late 2021 or early 2022) seems at first sight quasi-impossible to develop this AIF architecture. We start from the hypothesis that there is a special interest for the second round of investors who will form the critical mass for BSE (Bucharest Stock Exchange) in search of new risk-return opportunities. We refer to the dynamics of the future evolution and thus such an approach is justified. In this context the most important alternative strategies for a veritable HF could not be used by the portfolio manager. Compensation for the reduced possibilities of using tools and strategies is based upon this innovative architecture with satellite rotating sub-portfolios. It is also critical to understand the new strategies adapted for the actual volatile picture of global emerging markets and in the context of post-crisis recovery. In this new context it is essential to cope with a different set of uncertainties with focus on understanding the mechanics of different flexible and innovative adaptation in order to design optimal strategies for active portfolio management.

\section{The inspiration for an innovative design of a Hedge-Fund architecture for emerging markets}

This contribution is critical for all alternative investment funds and portfolio managers but also for researchers and specialists in the field of alternative investment funds (AIFs). This study is also useful for the creation of an extended knowledge in the field of active portfolio management in emerging markets based on a better capability for long term learning of emerging markets. The application is dedicated for the active selection of the sub-portfolios of a hedgefund in Romanian capital markets [5], [6], [7], [8]. Hedge funds (HFs) represent private investment vehicles capable to manage diversified portfolios (not only listed instruments like stock and bonds but also derivatives). In Romanian capital market there are a lot of constraints related to the capability of diversification management but the hedge-fund architectures benefiting could benefit from the multiple impact of alternative strategies. In this case it is possible to select instruments from an extended set of alternative strategies with long-term or short-term investment objectives taking the advantage of momentum movements in both directions of the markets. The critics of hedge-fund architectures in emerging markets note the impact of a narrow niche of investors attributed to the low culture of investments in capital markets. In this proposal, although the analysis addresses emerging markets, it will be shown that there are real possibilities to implement innovative-retail strategies and in this case the capabilities of hedge funds will be intelligently exploited. Although this seems surprising in the context of cultural 
leap, it is based on the significant progress in artificial intelligence and big-data analysis with impact on the real capabilities of portfolio management. Although hedgefunds can access (in theory) an extended set of strategies, in the case of emerging markets there exists constraints on implementation due to the limited possibilities of diversification and the liquidity of the markets. In our proposal we try to understand how to use multiple rotating strategies based on innovative selection of sub-portfolios. In order to adjust risk-return to the aim of retail investors it is also essential to implement an efficient risk control, in a context with derivative-based strategies constraints (and with highly nolinear cash flows), a limited capability of simultaneously mixing of long and short instruments, and finally the real capability to engage in short term short-strategies as a possible response to bear periods.

The first step of our research methodology is related to the sub-portfolio selection under the proprietary concept of the rotating sub-portfolio strategy [9], [10]. Beyond the conventional instruments (stocks, bonds, other fixed-income money market instruments) our focus is on the analysis of the real possibilities to new types of subportfolios: venture capital/ private equity funds (VCFs/ PEFs) and exchange traded funds (ETFs). The main problems in portfolio management are related to the Venture capital (VCFs) and private equity funds (PEFs)- sub-portfolio. Although VCFs and PEFs have some different characteristics, we consider them together because they offer similar architectures (close-end funds with long investment objectives and high returns associate to low liquidity). $\mathrm{VCFs} / \mathrm{PEFs}$ are particularly effective in supporting latent and emerging entrepreneurship with agile implementation capabilities. The actual architectural structure of entrepreneurial financing is oriented on debt but the trend is focused on more equity financing partnerships. The typical duration of VCFs/ PEFs is 8-12 years with possibilities of further extension by 1-2 years (with a first 5 years period of the investment, and a second period dedicated for maturing the investments and value capturing). In VCFs/ PEFs is essential to harmonize agent-principal relationships in a long-term partnership in order to cope with illiquidity constraints. Next, in order to better attract all types of investors, is essential to understand the way in which asymmetric information problems influence the persistence of a socially sub-optimal architecture. The typical dynamics of the volume of VCF / PEF financing in emerging markets is very attractive but we assist at a lack of investment culture coupled with a new status of entrepreneurial culture (with high interest for the capitalization of their companies). This is an interesting topic of our research because it is possible to assist at a competitive dynamic of entrepreneurial segments (the entrepreneurial segment, AERO, at Bucharest Stock Exchange BSE is in a special period with a lot of pre-public offerings and listings) with new synergies between knowledge, advanced technology and innovative financing capacity. The recent development of AERO-BSE segment will attract new investors, including retail one with a hope of creating the real critical mass to streamline future rounds of entrepreneurial financing. VCFs/ PEFs face high uncertainties, and all these portfolio elements could influence the performance of this sub-portfolio. There is a preference for segments of entrepreneurial business with short-term favorable dynamics like innovation (information and computer technology ICT, electric vehicles EVs, future internet, genomic techs GTs, robotics, space applications) and in this case it is important to understand also the long-term risks. VCFs/ PEFs could benefit in all these high-tech sectors from collaborative effects resulting from TripleHelix paradigm in the new context of NPRR 2021 (National Plan for Resilience and Recovery 2021). Next, we go beyond the diversification through instruments (VCFs/ PEFs), and we consider the double 
diversification, through alternative instruments and alternative strategies (in the context of the whole hedge-fund portfolio).

\section{Methodology and results- three approaches}

The development of a methodology for design and testing of an innovative investment vehicle with a very complex architecture but without specific data is very difficult. There are practically no starting points for such research in specific emerging markets (where there are no AIFs of this type). Therefore, we will try to develop a specific conceptual basis on which to build in a scalable way a suitable way of conception and testing. In our methodology we use three types of models for active portfolio management. The interest is to understand aspects like active sub-portfolio selection and the decision-making processes for subportfolio rotation in the case of our innovative HF dedicated for alternative investment funds (AIFs) in emerging markets, the case of Romanian capital market. The three approaches are the following:

\section{a) The Guy Serraf paradigm applied to} active portfolio management of HFs

The first approach is based on the Guy Serraf paradigm and we can consider different types of sub-portfolios (SPs): value sub-portfolios (that continuously generate future cash flows); sub-portfolios situated at the edge of their life cycle (here we include also overvalued stocks and stocks sensitive to future movements of interest rates); emerging sub-portfolios (growth stocks); in this case we also include a sub-portfolios for stocks situated in a short-term downward dynamics but good long-term perspectives. In this approach are not found under the portfolio with declining performance and low liquidity (which cannot be easily liquidated). Also, for emerging markets it is also possible to include a special sub-portfolio for special opportunities, like SPs with high returnhigh risk long-term perspectives but restricted by illiquidity problems.

\section{b) The BCG analogy applied to active portfolio management of HFs}

In the second approach based on the BCG (Boston Consulting Group) analogy we configure the portfolio of the HF based on four types of sub-portfolios according to the risk-return profile and the estimated future dynamics of development.

The profitability of the investment subportfolio is represented on the horizontal axis (price - earnings ratio PER of the typical segment and could be expressed by a market index or another benchmark) while on the vertical axis the future growth prospects of the market segment (based on fundamental analysis). The different subportfolios are marked within the matrix with the help of circles that by diameter / surface suggest the dynamics of evolution. The four quadrants in the BCG matrix classify sub-portfolios according to the profitability and growth perspectives and have the following specific generic names: SP1. „Stars” (High-High) represents subportfolios with both profitability and growth perspectives (for example the category value stocks).

SP2. „Dilemmas” (Low-High) represents sub-portfolios with good perspectives, and are interesting for long term performance (for example the category growth stocks)

SP3.,Cash-cows” (High-Low) represents sub-portfolios with robust capabilities to generate short-term results (for example the category high dividend stocks/ high yield bonds) and are also good liquidity buffers for difficult periods (this sub-portfolio could generate the liquidity for reinforcement the first and second type of sub-portfolios, SP1 and SP2);

SP4.,,Dogs" (Low-Low) represents subportfolios with modest profitability and bad future perspectives and should be reduced or eliminate.

The strategy is to understand the rotation timing (SP2 into SP1) and the use of SP3 as a liquidity buffer for SP1, according to market conditions. 


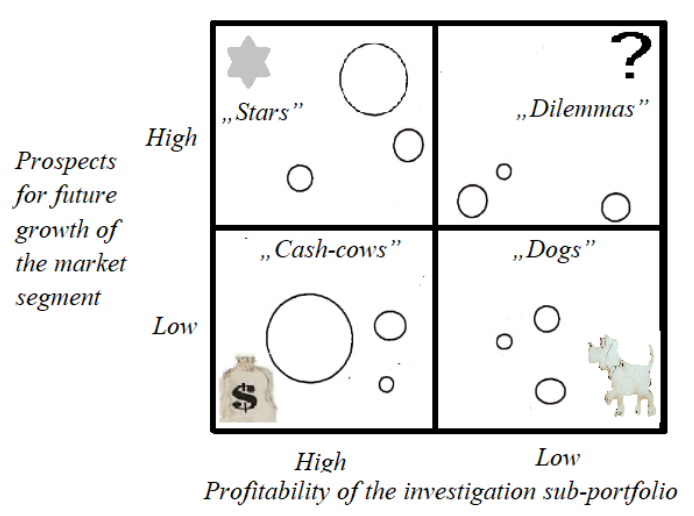

Figure 1: The BCG analogy applied to active portfolio management of HFs

c) The Mc Kinsey matrix applied to active portfolio management of HFs

In the third approach dedicated for emerging markets we propose a methodology for sub-portfolio selection and management based on Mc Kinsey matrix and in this case, we can identify 9 types of sub-portfolios according to their competitive position and attractivity. In this case it is a special focus on the momentum strategies related to the sub-portfolio rotation.

In this approach the $3 \times 3$ matrix aims to rank the efficiency levels of the subportfolio starting from a two-axis representation. The horizontal axis suggests the internal competitive position and the vertical axis the relative attractiveness with the external market segments. The internal competitive position and the attractiveness of the external market are determined starting from the identification of the success factors for the sub-portfolio, the creation of a list with the identified factors, the weights associated with these factors and finally the calculation of the scoring for each factor. These sub-portfolios are marked within the matrix with the help of circles whose diameter indicates a suggestive way of classifying the subportfolio projects according to the internal competitive position and the attractiveness of the external market.

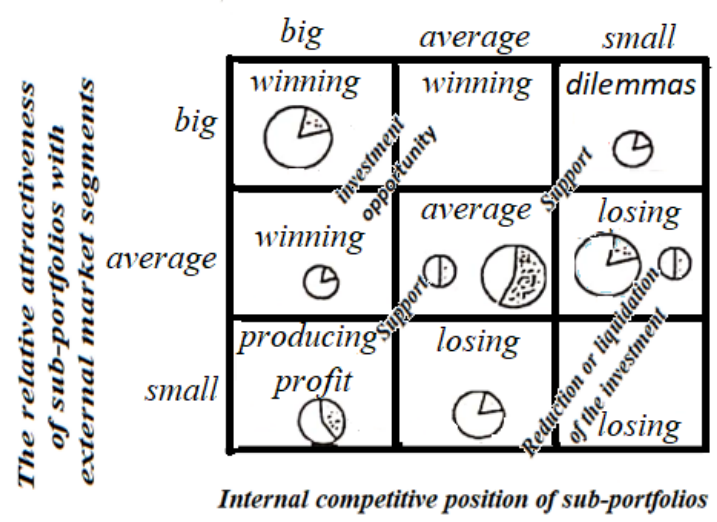

Figure 2: The Mc Kinsey matrix applied to active portfolio management of $H F s$

The Mc Kinsey matrix highlights the 3 "winning" quadrants, located in the NW corner and signifies an investment opportunity in relation to global markets and the 3 "losing" quadrants, located in the SE corner suggest the reduction or liquidation of the investment due to the relative loss of competitiveness in relation to global external markets.

\section{Conclusions and contributions}

The main contribution is related to the development of a new scalable and modular framework for active portfolio management in the case of Romanian AIFs in a HF architecture useful for understanding the dynamic adaptation all of alternative investment portfolios in different emerging market contexts. The realization of an HF architecture with rotating sub-portfolios is an innovative way to capture the advantages of a pure HF (alternative strategies are beyond alternative instruments a better and more efficient way to control the riskreturn-liquidity equation) in the context of adverse problems related to the market inefficiencies. In addition, the question of volatility in emerging markets put an additional pressure on portfolio management. This innovative architecture of $\mathrm{HF}$ is scalable and offer an intuitive understanding of the way of sub-portfolio selection and rotation according to the real dynamics in global capital markets. 


\section{References List}

[1] Boscoianu, M., Ceocea, C., Vladareanu, V., Vladareanu, L., „Special purpose vehicles for sustainable finance of innovation in Romania - the case of intelligent robotic systems”, „Periodicals of Engineering and natural sciences”, vol 8 no 3/ 20204 A, ISSN 2303-4521, http://dx.doi.org/10.21533/pen.v8i3.1518.

[2] Boscoianu, M., Prelipcean, G., „The creation of flexible special purpose vehicles (PPPEquity Fund) architectures for stimulating the innovative SMES”, „Business Excellence Chellenges during the Economic Crisis", vol 1, pp. 82-85, 2012.

[3] Boscoianu, M., Prelipcean, G., Lupan, M., „Innovation enterprise as a vehicle for sustainable development- A general framework for the design of typical strategies based on enterprise systems engineering, dynamic capabilities, and option pricing”, „Journal of Cleaner Production", vol 172, 2018.

[4] Prelipcean, G., Boscoianu, M., „Some aspects regarding the dynamic correlation between different types of strategic investments in Romania after integration", "Mathematics and Computers in Business and Economics", 2008.

[5] Prelipcean, G., Boscoianu, M., „Risk analysis of a hedge fund oriented on sustainable and responsible investments for emerging markets”, „Amphitheatre Economic”, Volume: 22, Issue: 55, pp: 653-667, DOI: 10.24818/EA/2020/55/653, Published: AUG 2020.

[6] Prelipcean, G.,Boscoianu, M., 2020, „An Innovative Flexible Investment Vehicle Oriented to Sustainability - The Adaptation of Hedge Funds in the Case of Emerging Markets”, pp. 493-503, „Proceedings of the ENTRENOVA - ENTerprise Research InNOVAtion Conference", Virtual Conference, 10-12 September 2020.

[7] Prelipcean, G., Boscoianu, M., 2019, „Aspect Regarding the Design of Active Strategies for Venture Capital Financing - the Flexible Adjustment for Romania as a Frontier Capital Market”, ,Proceedings of the ENTRENOVA - ENTerprise Research n InNOVAtion Conference", Rovinj, Croatia, 12-14 September 2019, pages 187-196, IRENET - Society for Advancing Innovation and Research in Economy, Zagreb.

[8] Prelipcean, G., Boscoianu, M., Lupan, M., Nastase, C. E., „Innovative financing solutions based on Venture Capital and Private Equity to support the development of entrepreneurship in Romania”, „Transformations in Business \& Economics 13”, 2014.

[9] Ethiraj S., Levinthal D., (2004) "Modularity and innovation in complex systems", Manag Sci 50:159-173.

[10] Shintaku J., Amano H., (2009) "Emerging market strategies: changes in market and resource strategies”, MMRC Discussion Paper 278. 